\title{
Cultural Changes in Neural Structure and Function
}

\author{
Michael E. W. Varnum ${ }^{1} \&$ Ryan S. Hampton ${ }^{1}$ \\ ${ }^{1}$ Arizona State University
}

\begin{abstract}
Human cultures are not static. An emerging body of research has documented cultural changes in a wide variety of behaviors, psychological tendencies, and cultural products. Increasingly, this field has also begun to test hypothesis regarding the causes of these changes and to create forecasts for future patterns of change. Yet to date, the question of how our brains may change as a function of systematic changes in our environments has received relatively little attention and scant empirical testing. In the present chapter we begin by reviewing the literature on cultural change, including Varnum and Grossmann's program of research using a behavioral ecology framework to understand patterns of cultural change. Next we offer some initial predictions for changes in neural structure and function that may occur in the coming decades and we discuss implications for global mental health. Finally, we offer some ideas about how empirical research testing these predictions might be conducted and discuss challenges and opportunities for extending the study of cultural change to neuroscience.
\end{abstract}

Keywords: Cultural Change, Cultural Evolution, Behavioral Ecology, Cultural Neuroscience, Cultural Psychology 
How and why do human cultures change? In recent years social psychologists have developed increasingly sophisticated methods to document changes over time in human behavior and psychological tendencies and to test theories regarding the causes of these shifts (Greenfield, 2016; Kashima, 2014; Varnum \& Grossmann, 2017a). However, to date this work has focused largely on changes in cultural products, attitudes and values, performance on psychological tests, and behavior. In this chapter we attempt to envision a framework to study cultural changes using neural methods. In doing so we draw on a diverse set of theoretical perspectives including cultural psychology, cultural neuroscience, behavioral ecology, and evolutionary psychology.

First we summarize extant research documenting cultural changes in wide variety of phenomena ranging from individualism/collectivism to life history strategies. We also discuss evidence regarding the causes of many of these changes which appear to be linked to adaptive responses to key dimensions of ecology. Next, we offer a set of tentative predictions for changes that may be occurring in neural structure and function as result of changes in the ecology (i.e. increased population density and mobility), changes in technology (i.e. the advent of online social networks and widespread use of GPS-based navigation), and as a result of changes in the prevalence of mental health issues (i.e. increasing levels of anxiety and depression). We also discuss implications of these changes for changes in prevalence of a number of mental health problems in a global context. We then address methods that would allow these predictions to be tested, providing a possible roadmap for large-scale neuroscience studies of cultural change and highlighting key methodological issues that would likely be encountered in such an enterprise. Finally, we end by discussing both the promises and challenges of a future neuroscience of cultural change.

\section{Cultural Change}

\section{Individualism}

Perhaps the most studied phenomena in research on cultural change has been individualism/collectivism, which can be broadly thought of as an emphasis on the individual self and a view of the self as separate from others vs. an emphasis on relationships and a view of the self as fundamentally intertwined and interconnected with others (Markus \& Kitayama, 1991; Nisbett, Peng, Choi, \& Norenzayan, 2001; Triandis, 1995; Varnum, Grossmann, Kitayama, \& Nisbett, 2010). Levels of individualism have risen dramatically over the past several decades (and even over the past two centuries) in the United States as indicated by increasing use of words reflecting individualist values (Greenfield, 2013; Grossmann \& Varnum, 2015; Twenge, Campbell, \& Carter, 2014) as well as first person singular pronouns (Twenge, Campbell, \& Gentile, 2013) in American books. Other indicators of individualism show the same effect, including increasing frequency of relatively unique names (Grossmann \& Varnum, 2015; Twenge, Abebe, \& Campbell, 2010), higher rates of divorce (Grossmann and Varnum, 2015), and increasing endorsement of individualistic values (Santos, Grossmann, \& Varnum, 2017). Similar effects have been observed in the US (Greenfield, 2013), China (Cai, Zou, Feng, Liu, \& Jing, 2018; Hamamura \& Xu, 2015; Zeng \& Greenfield, 2015), Japan (Hamamura, 2012; Ogihara, in press). These shifts are not confined to handful of countries, and in fact individualism appears to have increased (at least over the past 50 years) in the majority of societies around the 
globe including countries as diverse as Chile, India, and Nigeria, Russia, and Turkey (Santos, Varnum, \& Grossmann, 2017). In a similar vein, levels of conformity, a phenomenon linked to collectivism, also appear to have declined over time (Bond \& Smith, 1996).

\section{Self-Esteem and Narcissism}

Another major area of inquiry has been whether levels of self-esteem and related variables have changed from 1960's to the present. In one study, Twenge and Campbell (2001) found that American children's average levels of self-esteem decline from 1965 to 1979 and increased from 1980 to 1993. In a similar vein, several studies have documented increases in narcissism from the 1950's to the 1990's among American college students (Roberts \& Helson, 1997; Twenge \& Foster, 2008; Twenge, Konrath, Foster, Campbell, \& Bushman, 2008). Other evidence suggests that beliefs in illusory superiority have also increased among American college students from the 1960's to the 2000's (Twenge, Campbell, \& Gentile, 2012a). However, other researchers have found that levels of narcissism and self-enhancement among American college and high school students remained fairly stable from the 1980's to the mid-2000's (Trzesniewski, Donnellan, \& Robins, 2008b, 2008a), and the claim that narcissism has continued to rise has been challenged by researchers who have demonstrated a lack of measurement equivalence over time on a commonly used narcissism inventory and find that controlling for measurement inequivalence there has in fact been a decline in narcissism among US college students from the 1990's to the 2010's (Wetzel et al., 2017). Further, a recent cross-temporal meta-analysis of studies measuring self-esteem among Australians shows a slight decline in levels of self-esteem from the 1970's to the 2010's (Hamamura \& Septarini, 2017). Thus at present the evidence is mixed regarding shifts in self-esteem and related variables over the past several decades.

\section{Well-Being and Emotions}

Are people becoming more or less happy over time? A number of converging lines of evidence suggest that Americans at least are becoming less happy. The percentage of positive vs. negative language used in American books and a leading national newspaper has declined substantially from 1800 to present (Iliev, Hoover, Dehghani, \& Axelrod, 2016). Further, selfreported subjective well-being declined from the 1970s to the late 2000's according to data from the General Social Survey (Oishi, Kesebir, \& Diener, 2011). The prevalence of depressive and anxious symptoms has increased markedly from the 1930's to the 2000's (Twenge, Gentile, et al., 2010) according to a cross-temporal meta-analysis of studies using the MMPI. Further, nationally representative data from US high school students shows an increase in self-reported symptoms related to mood disorders from 1982 to 2013 (Twenge, 2015). Further analysis of CDC data shows an increase in suicide rates among in nearly all US states between 1999 and 2016 (Stone et al., 2018). Interestingly, as Americans have become less happy they also appear to have become less contemptuous. Varnum and Grossmann (2017b) analyzed the frequency of contempt-related language in American books and movies and found a dramatic decrease over time from the early $20^{\text {th }}$ century to the mid 2000's. More recently, research has linked increasing use of new media (i.e. social media, smartphones) to increasing rates of mental health issues among American adolescents (Twenge, et al., 2018). Thus Americans appear to have become markedly less happy over time. However, this trend does not appear to be universal. In fact, 
according to data from the World Values Survey, most societies have become happier from the 1980's to the present (Roser \& Ortiz-Ospina, 2017).

\section{Social Capital and Gender Equality}

Researchers have also assessed changes in the way societies are organized in terms of relationships to institutions, attitudes regarding how society should be structured, and related social norms and practices. In a set of seminal studies on cultural change, the political scientist Robert Putnam documented a set of changes in American society from the 1950's to the 1990's that he dubbed a decline in social capital (Putnam, 1995, 2000). During this time period Putnam found a decline in civic participation, membership in voluntary organization, and levels of general trust. More recently, Twenge and colleagues found that trust in others and confidence in a wide variety of institutions declined among American adults and adolescents over a 40 -year period from 1972-2012 (Twenge et al., 2014). Interestingly though this pattern was not observed in a recent study examining levels of trust in 34 European societies, with trust remaining fairly stable from 2002-2012 (Olivera, 2015).

Another area of marked change has been in the arena of gender equality. Survey data shows a sizeable increase in the US in support for policies favoring equality among the sexes from the 1960's to the 2000's (Thornton \& Young-DeMarco, 2001). Complimentary evidence from a cross-temporal meta-analysis of studies using the Attitudes Toward Women scale, which found greater support for feminism among men and women from the 1970s to the 1990's (Twenge, 1997), and from an analysis of cultural products which found greater parity in the use of female and male pronouns in American books (Twenge, Campbell, \& Gentile, 2012b). More recently, Varnum and Grossmann (2016) constructed an index of gender inequality using a combination of indicators including male:female wage ratio, male:female pronoun use in books, female political representation, and sexist work attitudes. From the 1950's to the 2010's this index showed a dramatic decline in the US and from the 1940's to the 2010's a similar index showed the same effect in the UK.

\section{Relationship with the Natural World}

Other work has explored shifts in societies think about and engage with the natural world. In their analysis of references to nature in cultural products, Kesebir and Kesebir (2017) report a decline in nature-related language (i.e. references to birds, trees, flowers, seasons, etc) in American and British fiction, popular song lyrics from Anglophone countries, and storylines from Anglophone films from the mid-twentieth century onwards. Interestingly though, for mentions of nature in fiction appear to have increased somewhat from 1900 to 1950 and declined thereafter.

Although an emphasis on the natural world appears to be on the decline in cultural products, recent work suggests that climate change may increase the amount of time people spend outdoors in much of the US. Using data from 2002-2012 Obradovich and Fowler (2017) find that recreational physical activity is linked to fluctuations in temperature and other climatic factors, and that projections for effects of climate change suggest that in large swaths of the North, Midwest, and Pacific Northwest levels of outdoor physical activity should increase over the $21^{\text {st }}$ century, whereas they are likely to decrease in parts of the Southwest and South. 


\section{Preference for Complexity}

Cultural changes have also been observed in preference for complexity. Cultural products, such as songs, television shows, visual art, literature, and political speeches vary in terms of the complexity of the ideas or information presented. Although some have argued that such cultural products show evidence of increasing average complexity in the recent years (i.e. Johnson, 2006), only more recently has this proposal been subjected to empirical tests. In an analysis of song lyrics from over 14,000 songs entering the Billboard charts from the 1958 to 2016 Varnum and colleagues (Varnum, Krems, Morris, \& Grossmann, 2018) found that lyrics of popular songs have become increasingly repetitive. Further, forecasts using Auto-ARIMA suggest that this trend will continue for the next several decades and that this effect is driven in part by greater amounts of music being produced in a given year. This preference for reduced complexity is also evident in the language used by successful American politicians, namely American presidents. Pennebaker and colleagues (2018) show that over the past century speeches by American presidents show diminishing levels of analytic language, suggesting a trend toward preference for leaders with simpler styles of expression.

\section{Intelligence}

Intelligence has also been a key topic in the study of cultural change. In several countries large increases in fluid and crystallized intelligence have been documented from the 1930's into the late $20^{\text {th }}$ century. This phenomenon is dubbed the Flynn effect (Flynn, 1987) and has also been observed in several cross-temporal meta-analyses, including studies extending the effect into the 2010's (Pietschnig \& Voracek, 2015; Raven, 2000; Trahan, Stuebing, Hiscock, \& Fletcher, 2014). Further, as some have argued that there are multiple flavors or types of intelligence, beyond cognitive capacities that have typically been studied (Gardner, 2011; Sternberg, 1985), it is interesting to note that athletic performance in a wide variety of sports has increased considerably during the past century (Kaufman, 2013).

\section{Life History Strategies}

Finally, there is also evidence in the US and many other societies of a shift toward slower life history strategies. Life history strategy refers to a suit of physiological and behavioral dimensions related to the timing of reproduction, delay of gratification, and an orientation toward future or present, which have been found to vary across species and among groups and individuals within-species, including humans (Charnov, 1993; Del Giudice, Gangestad, \& Kaplan, 2015; Kenrick \& Griskevicius, 2015; Sng, Neuberg, Varnum, \& Kenrick, 2018; Stearns, 1992). Fast life history strategies involve early reproduction, greater number of offspring, greater risk taking, reduced delay of gratification, and shorter life expectancies, whereas slower life history strategies involve delayed reproduction, fewer offspring, greater investment in offspring, delay of gratification, investment in long term outcomes, and longer lifespans. Sociologists and demographers have long noted a demographic transition in which life expectancies have increased and birth rates have decreased (i.e. Lesthaeghe, 2015). Further, recent studies have found declining rates of teen pregnancy in the US and UK (Varnum and Grossman, 2016) and evidence of a shift toward slower life history behaviors among American adolescents over the 
past four decades (i.e. reduced sexual activity, less participation in the workforce, and decreased prevalence of adult activities (Twenge \& Campbell, 2018; Twenge \& Park, 2017).

\section{Why Do Cultures Change?}

\section{Modernization Theories}

Modernization theories argue that a variety of recent changes in human societies can be understood as the results of economic development. With greater economic development, according to these accounts, a cluster of changes have occurred in values and practices that are linked to institutional changes and a broad range of other phenomena (Inglehart, 1997; Inglehart \& Welzel, 2005) including more emphasis on individual autonomy and freedoms, greater tolerance, and democratic institutions. In this view, as greater numbers of people in a society become able to meet basic needs, their goals and values shift in the direction of individualism, self-expression, freedom, and tolerance. Such preferences and beliefs reflect more abstract concerns, which people can afford to attend to once they have sufficient food, shelter, security, etc.

In a similar vein, Greenfield's theory of cultural change and human development, which holds that a host of changes have occurred simultaneously in the past couple centuries, urbanization, industrialization, and loosening of family ties, have led to rising individualism as well other cultural shifts such as greater innovation, more abstract reasoning, and greater tolerance (Greenfield, 2013, 2016, 2017). In this view, modern urban living in market economies pushes individuals toward greater focus on their own goals and outcomes, weakness traditional social bonds, and encourages modes of reasoning and values that are more conducive to success in these changed social conditions.

Although these theories have been highly influential, in some regards the answers they provide can be seen as theoretically shallow. Typically research in this tradition is not grounded in evolutionary logic, nor does it tend to assess the relative importance of various factors which are theoretically orthogonal to the changes that these theories seek to explain. In addition, these frameworks offer somewhat intermediate as opposed to ultimate explanations for observed cultural changes and often do not conceptually or empirically assess which variables in these models are endogenous vs. exogenous. Such theories also tend to view all observed societal changes that have occurred in recent decades or centuries as part of the same broader process. However, this research in many ways provided an excellent starting point for more recent work on cultural change by documenting a variety of cultural changes and by pointing to structural changes that might be linked to them.

\section{Ecological Theories}

Other theories regarding the causes of cultural change emphasize the role of ecology. Some of these studies explicitly adopt a behavioral ecological framework, emphasizing how variations across and changes within human societies may be understood as driven by evoked adaptive responses to recurring environmental threats and affordances, such as infectious diseases, population density, resource availability, mortality threat, and relatedness, originally derived from research on other species (Sng, Neuberg, Varnum, and Kenrick, 2018; Varnum \& Grossmann, 2017). To this list of key ecological factors, we might also add climatic stress (Van 
de Vliert, 2013) and income inequality which is arguably a proxy for resource patchiness in modern human societies (Sng et al., in press). In a long running collaboration, Igor Grossmann and I have used this framework to assess the causes of a variety of cultural changes.

We have done so by simultaneously testing the unique contribution of multiple ecological dimensions and by using techniques like cross-correlation function analysis and granger causality analysis to assess temporal precedence and more recently auto-ARIMA modelling and Tiokhin-Hruschka (2017) null distribution methods for correcting significance thresholds in order to assess whether these relationships hold accounting for temporal autocorrelation observed in the time series (Varnum, 2018; Varnum, Krems, Morris, and Grossmann, 2018). We have found that shifts in individualism are most strongly linked to changes in markers of resource availability, with greater levels of white collar jobs, education, and income emerging as stronger and more consistent predictors of increasing individualism than other ecological dimensions (Grossmann and Varnum, 2015; Santos, Varnum, and Grossmann, 2017). We also found that indicators of resource levels were the best predictor of changes in expressions of contempt over time (Varnum and Grossmann, 2017b). Further, we recently examined the relationship between innovation and GDP per capita in the US and UK during the first and second industrial revolution and into the present. We find evidence in both countries (after using first order detrending) that there appear to be bidirectional lagged relationships between rising resource levels and innovation (i.e. patents, trademarks, unique book publications), suggesting that as sociteis become more materially secure their members are more willing to generate novel ideas, and vice versa (Varnum and Grossmann, 2018). These results are generally consistent with the predictions of modernization theory as well as those of behavioral ecology. However, we also observed some relationship between declining pathogens and rising levels of individualism and declining contempt, as well as contributions by markers of increasing population density to rising individualism, and some evidence of an interaction between climatic stress and resource levels predicting levels of individualism over time (Grossmann and Varnum, 2015; Varnum and Grossmann, 2017b; Santos, Varnum, and Grossmann, 2017). The strongest predictor of increases in gender equality appears to be declines in rates of infectious disease, an effect partially mediated by a shift toward slower life history strategies among women as indexed by teen birth rates (Varnum and Grossmann, 2016). Further, this line of research found empirical evidence that changes in resource levels temporally precede changes in individualism and that changes in pathogen levels temporally precede changes in gender equality (Grossmann and Varnum, 2015; Santos, Varum, and Grossmann, 2017; Varnum and Grossmann, 2016). This work suggests that cultural change on varied dimensions is not monolithic, but rather that specific changes appear driven by specific ecological shifts. In a similar vein, recent work by Twenge and Park (2017) found links between markers of resource availability and pathogens levels and changes in the prevalence of adult activities among American adolescents, such increases in markers of resource abundance and decreases in pathogen prevalence are linked to declines in the frequency adult activities, indicative of a shift toward slower life history strategies.

Other research has also found links between ecological factors and cultural changes without adopting an explicitly behavioral ecological framework. For example, declining levels of subjective well-being appear linked to measures of income inequality (Oishi, Kesebir, and Diener, 2011) and reductions in linguistic positivity bias appear linked to levels of unemployment and inflation (Iliev et al., 2016). Similarly, Bianchi (2016) has found strong links between unemployment levels and cultural shifts in individualism. Other research has linked levels of income inequality to changes in levels of social capital (Twenge, Campbell, and Carter, 
2014). Finally, a series of studies by Obradovich suggests that changes in climate (increasing maximum temperatures and average precipitation) are linked to a variety of cultural phenomena ranging from electoral turnover (Obradovich, 2017) to rising levels of mental health difficulties (Obradovich et al., 2018) and that continuing climate change is likely to accelerate these social shifts in the decades to come. Taken together, these lines of research suggest that changes in basic dimensions of our physical and social ecologies may be key to understanding and predicting patterns of cultural change.

Finally, in recent work my colleagues and I have begun to consider other aspects of the ecology that speak to information or choices available in the environment. We find for example, that increases in preference for lyrically simple popular music over time appear to be driven by increases in the amount of novel musical choices available in a given year, an effect which holds controlling for standard behavioral ecological dimensions as well as immigration and residential mobility (Varnum, Krems, Morris, and Grossmann, 2018). Others have proposed that the Flynn Effect on intelligence might be due to increasingly stimulating environments, including greater exposure to more complex visual media, modern technology, and more stimulating work environments (Flynn, 2007). Taken together this work suggests that it may be useful to expand an ecological framework to encompass environmental features of the informational landscape and suggests potential links between a behavioral ecological approach to cultural change and cultural evolutionary frameworks (see Muthukrishna \& Uchiyama, this volume) which tend to focus on transmitted culture and the features of information and human information processing biases which also adaptively shape culture over time (for a more detailed discussion of the differences between these approaches and potential synergies see Varnum and Grossmann, 2017a).

\section{How Have/Will Our Brains Change?}

At the core of cultural neuroscience is a set of premises: that the human brain is plastic and shaped by repeated experiences, that cultural contexts can provide systematically different sets of experiences, and that to the extent that such contexts provide different sets of experiences we should expect corresponding differences across cultural groups in neural function and structure (Chiao \& Blizinsky, 2016; Han, 2013; Kitayama \& Uskul, 2011). For a more in depth discussion of culture and neuroplasticity, see Goh (this volume) and for a more in depth discussion of the philosophical meaning of cultural differences in neural structure and function, see Northoff (this volume). Consistent with these ideas, in the past decade, dozens of studies have indeed found differences in neural function and structure across cultural groups (Hampton \& Varnum, 2018a; Han \& Ma, 2014; Kim \& Sasaki, 2014; Kitayama, Varnum, \& Salvador, in press). For example, recent ERP studies have found that European-Americans show evidence of an implicit positivity bias for the self, whereas Chinese do not appear to show this bias (Hampton \& Varnum, 2018b) and that European-Americans (and those from Mexican cultural backgrounds) are better able to intentionally up-regualte neural affective responses than people from East Asian cultural backgrounds (Varnum \& Hampton, 2017; Hampton, Kwon, \& Varnum, under review). Further, research using fMRI has found that the neural substrates involved in processing self-relevance appear culturally influenced; Chinese show comparable activation in the Mpfc when making judgments regarding the relevance of adjectives to the self and one's mother, whereas Westerners show greater activation in this region for self vs. mother relevant judgments (Zhu et al., 2007). Other research suggests that there may be structural correlates of 
different modes of construing the self, with interdependent self-construal - - a view of the self as overlapping and interconnected with close others that is more predominant in East Asian cultures (Markus \& Kitayama, 1991; Varnum et al., 2010) - - being linked to reduced volume in the orbitofrontal cortex (Kitayama, et al., 2017). These findings represent only a small portion of the broad and expanding empirical literature documenting cultural influences on neural responses and neural structure. Taken together, this work suggests that culture does indeed have a measurable effect on how the human brain is structured and how it functions.

This body of literature has implications not only for understanding how brains may differ across cultural groups, but also for predicting how brains may change over time as changes occur within a cultural context. In this section we outline a set of predictions for neural changes at the population level in many societies that may occur due to shifts in ecology, use of novel technologies, and due to other cultural changes (see Figure 1 for relevant neural structures). This set of predictions applies broadly across societies as the trends that we believe will lead to neural changes are happening in a fairly global fashion. However, to the extent that societies vary in these exogenous trends, we would also predict variation in the degree to which we observe the predicted neural changes. And if there are reversals in the exogenous trends, then we would expect corresponding reversals in the predicted neural changes.

Figure 1. Brain areas for which we predict changes in average volume or connectivity over time. Images created using the Human Brainnetome Atlas template (Fan et al., 2016) and the Scalable Brain Atlas software program, (Bakker, Tiesinga, \& Kötter, 2015).

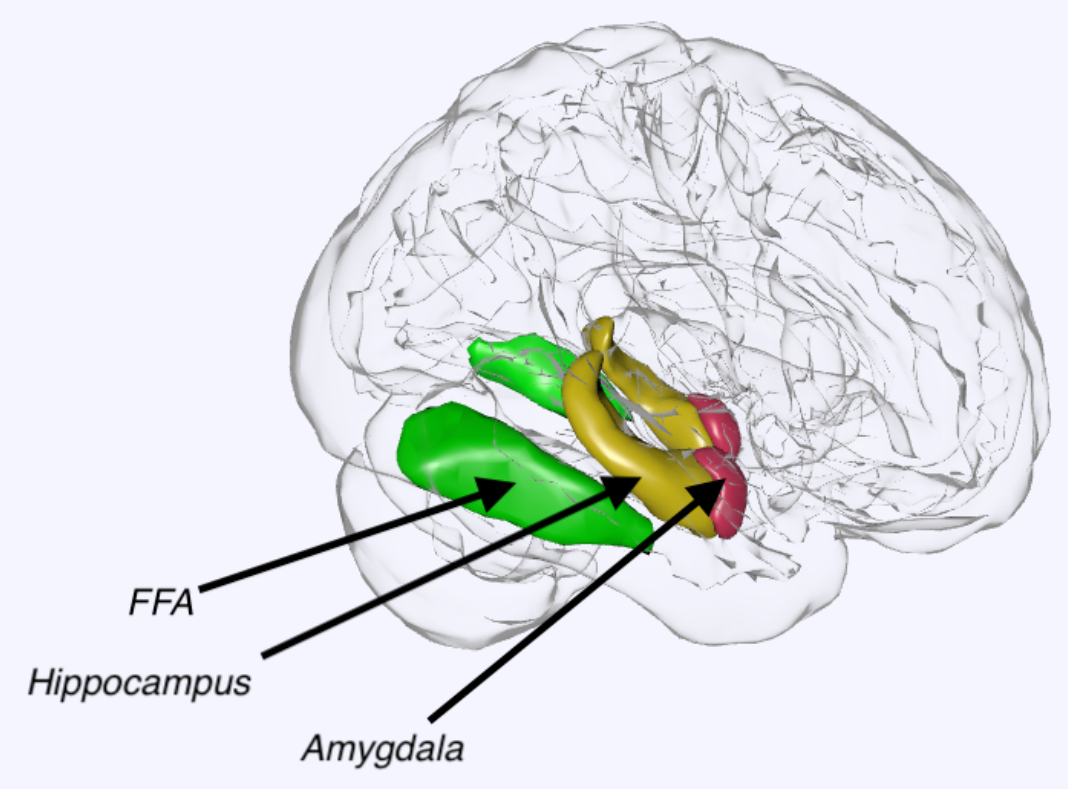




\section{Changes in Fusiform Face Area Volume}

In the past several decades (and centuries in many cases) most societies have experienced dramatic shifts in the distribution of their populations due to migration from rural to urban areas, as well as population growth, leading to increased population density (Roser \& Ortiz-Ospina, 2017; United Nations, 2014). Further, migration has increased (Martin, Weerasinghe, \& Taylor, 2014; United Nations, 2013) and travel has become more common (Schuttenhelm, 2016). In addition, the past decade has seen the development and widespread adoption of online social networks and video chat services. We suspect that as a result of these developments people in most societies have exposure to a greater number of individuals than in past. Thus, we propose that these changes should enhance the neural circuitry involved in people's ability to detect, differentiate, and identify human faces, in particular the fusiform face area. The fusiform face area is a region of the fusiform gyrus that research suggests is devoted to facial processing (Gauthier et al., 2000; Kanwisher, McDermott, \& Chun, 1997; Kanwisher \& Yovel, 2006; Sergent, Ohta, \& MacDonald, 1992). Thus to the extent that trends like urbanization, mobility, use of online social networks continue to increase within a given society, we would predict that we should observe increases in average volume of the fusiform face area among members of that society.

\section{Changes in Hippocampal Volume}

Another marked change in many societies has occurred in the past decade. The widespread adoption of accurate hand held artificial navigation technology. A key region involved in spatial navigation is the hippocampus (Ghaem et al., 1997; Maguire et al., 1998) and importantly individuals who develop high levels of expertise in spatial navigation (such as London taxi drivers) show greater hippocampal volume, suggesting plasticity in this region as function of experience among adults (Maguire et al., 2000). However, with the advent and widespread adoption of technologies such as mobile map apps, GPS, and other applications that provide step by step real-time directions, one would expect that in many societies individuals should show reductions in non-assisted navigational abilities. Hence to the extent that artificial navigation technologies are increasingly used in a society we should observe decreases in average volume of the hippocampus among its members.

\section{Changes in Amygdala Reactivity}

As noted earlier in this chapter, levels of well-being appear to have declined substantially in the US over the past century, with evidence of increases in the prevalence of anxiety and depressive symptoms. Recent work suggests that declines in the amount of time people spend engaged in deep real world social interactions (vs. online) and increases in the unpleasantness of weather (more heat, more rain) have led and will continue to lead to greater prevalence of mental health problems (Obradovich et al., 2018; Twenge, et al., 2018). What changes might we see in the brain as a result? Heightened reactivity of the amygdala to negative emotional stimuli has been associated with trait anxiety and neuroticism (Stein, Simmons, Feinstein, \& Paulus, 2007), social anxiety disorder (Bergman et al., 2014; Etkin \& Wager, 2007), and depression (Canli et al., 2005; Gaffrey et al., 2011; Redlich et al., 2018; Siegle, Thompson, Carter, Steinhauer, \& Thase, 2007). Thus to the extent that depression and anxiety become more prevalent in a society 
over time (due to changes in the social and physical environment), we would predict that we should see neural changes associated with these symptoms, particularly increased average reactivity of the amygdala to negative emotional stimuli.

\section{Implications for Mental Health}

Although our predictions regarding changes in average amygdala reactivity have fairly clear implications for anxiety and depression, it may also be the case that the structural changes we predict for the Hippocampus and FFA might also be relevant for making predictions regarding prevalence of a variety of mental health problems. Below we speculate about potential impacts of such changes on a variety of mental illnesses, drawing predictions based on associations observed in previous literature between these regions and these conditions, and we also discuss how such changes may play out in a global context.

If average hippocampal volume does indeed decrease in a given population, it is possible we might also expect an increase in incidence of depression, schizophrenia, and bipolar disorder, as previous research has linked atrophy in these regions to these conditions (Campbell \& Macqueen, 2004). Further, the hippocampus is implicated in memory, and some have speculated that certain memory impairments observed among people suffering Major Depressive Disorder may be linked to changes in Hippocampal structure or function (Campbell \& Macqueen, 2004).

Further, if FFA volume increases as a result of experience correspond to increased activation in this neural structure in response to faces, it may have implications for the prevalence of Autism. Research suggests that reduced activation in the FFA is associated with Autism Spectrum Disorder (Schultz, 2005; Schultz et al., 2003), a finding confirmed by a recent meta-analysis (Patriquin et al., 2016). Thus it may be that the changes that we forecast for this region may suggest that the prevalence of ASD may begin to decline in societies in which such changes occur. However, it is worth noting that some evidence has suggested that the FFA may be abnormally enlarged among those with ASD due to deficient neural pruning (see Schultz, 2005 for a review). Thus implications for changes in FFA volume for ASD prevalence rates are somewhat ambiguous.

Further, given To the extent that societies in the developing world are beginning to experience changes in their social and technological landscapes that parallel those that have recently occurred in more affluent societies like the US, UK, and Japan, we might expect increases (or decreases as the case may be) in the prevalence of mental health problems along these lines, and in many cases such changes in the prevalence of various symptoms may be more pronounced in these societies in the coming years as they begin to catch up with richer societies. This may pose unique challenges as in many developing countries mental illness is associated with greater stigma and there tends to be more limited access to mental health treatment. That said, we regard these predictions as even more speculative than our main predictions for culturallevel neural changes.

\section{How Can We Study Cultural Change at the Neural Level?}

In the following section we attempt to envision what a neuroscience of cultural change might look like. The logistical challenges such an endeavor would entail are non-trivial, but potentially surmountable given sufficient funding and motivation. Such an enterprise would also have to address other issues common to time series research, such as temporal autocorrelation, a 
problem which describe and offer potential solutions to in this section as well. Finally, as with other time series research using more traditional methods, for truly satisfying tests of hypotheses regarding cultural changes in neural structure and function it is necessary to develop models not only to explain past patterns of temporal change, but that can forecast future patterns based on these models.

\section{Sampling}

Assessing cultural change at the neural level will require coordinated data collection at a fairly unprecedented scale for research using MRI or fMRI (with the IMAGEN project providing a notable exception). In order to have confidence that data gathered for each time point are reasonably representative of the overall state of the society minimum sample sizes will likely need to be at least comparable to those used in large scale survey research (i.e. N's $>1000$ ) and selected so that they are demographically representative. It will also need to be gathered yearly for a minimum of several decades in order to have a chance of capturing meaningful patterns of cultural fluctuations or shifts in neural structure and function. Given the high cost and other logistical hurdles involved in data collection on this scale, it might seem tempting to instead sample individuals at a single timepoint from different birth cohorts, however this approach would make it difficult to rule out developmental factors as alternative explanations for any effects observed. Alternatively, one might opt for a cross-temporal meta-analysis design (for details of this approach see Gentile, Campbell, and Twenge, 2014). This approach although initially appealing, is limited by the fact that MRI/fMRI studies tend to have fairly small N's and by an important set of challenges in pooling data across MRI scanners. This latter issue is discussed in more detail in the next section of this chapter. Thus in an envisioning a future neuroscience of cultural change the gold standard would likely involve yearly structural and functional scans from large representative samples of a given society conducted on the same scanner, or the same set of scanners (and even this would involve tests for comparability of the data gathered on the same scanners over time), over the span of at least 5 decades and preferably over a much longer time span.

\section{Comparisons across Scanners/Testing Sites}

For the scale of data acquisition necessary to assess cultural change, the use of similar scanners across different sites or the use of the same scanners over time present substantial challenges in controlling for variance due to the machines used to acquire the data. The BOLD signal used in fMRI studies comprises a relatively small percentage of the overall signal acquired by a scanner, with random noise originating both from physical artefacts caused by the participant as well as fluctuations by the scanner (Liu, 2016; Matthews, 2001). Testing for and tracking the latter is critical in determining image stability across time on the same scanner and scanners. Assessing this stability is done primarily by characterizing the temporal signal-to-noise ratio (tSNR), defined as the mean amplitude divided by the standard deviation of noise over time (for a more in-depth definition see Liu, 2016).

The methods for testing scanner stability using the tSNR range from relatively simple approaches, such as plotting the tSNR as a function of the size of ROI (Weisskoff, 1996), to more complex modeling of the signal. Previous large-scale fMRI initiatives such as the Human Connectome Project (Marcus et al., 2013) using multiple scanning sites across time have 
employed the use of quality assurance tools such as the Agar phantom (Friedman \& Glover, 2006). This process uses a "phantom" plastic sphere filled with a doped agar gel to act as a static source of relative electrical silence (i.e. no areas are "activating") that mimics the conductivity of brain tissue. The phantom is scanned using the parameters meant for human data acquisition across all sites and time points and fed into a freely available QA tool (fmriqa_phantomqa.pl ${ }^{1}$ ). This tool gives indices of tSNR, percent signal fluctuation and drift, smoothness, scanner stability, and intensity of ghosting, or the presence of spontaneously large signals in certain ROIs. Recommendations for determining how much variance in tSNR and other QA measures warrants concern about system differences can be found in Simmons, Moore, and Williams (1999).

\section{Measuring Putative Exogenous Causes}

An important step in rigorous cultural change research is to empirically test putative causes of patterns of cultural change. In the case of the predictions we have outlined so far this would likely mean gathering time series data on population density, use of online social networks (and average size of such networks), use of GPS or computer assisted navigation, and rates of anxiety and depressive symptoms. It would also be wise to gather data on other factors previously linked to cultural change including markers of resource levels and infectious disease prevalence. Population-level data on these variables may be easier to come by than populationlevel neural time series data, but for many variables the span for which data is extant is limited. Thus providing tests of the causes of any observed neural changes will likely involve prospective studies.

\section{Common Issues in Time Series Research}

Perhaps the most vexing problem in research using time series data is ruling out spurious associations. This is especially true if that two time-series being assessed contain high degrees of autocorrelation (Tiokhin \& Hruschka, 2017; Vigen, 2015), two variables may appear to have a strong relationship when in fact the relationship is spurious and due simply to the fact that both exhibit a strong degree of autocorrelation. Some of the more humorous examples include correlations between marriages in Kentucky and fishing related deaths (Vigen, 2015) and mentions of Jennifer Lawrence in news media and the performance of the Dow Jones Index (Fawcett, 2015). In research on cultural change, the time series data sets we tend to be interested in are interesting precisely because they exhibit secular trends.

So how can researchers be confident that relationships they observe are not spurious? There are several approaches to this problem. One is simply to remove linear trends from the data using a method such as first-differences detrending (e.g. Tiokhin and Hruschka, 2017; Varnum and Grossmann, 2018), similarly one may assess associations between two time-series controlling for year (or other unit of time) using partial correlation analysis (e.g. Bianchi, 2016; Varnum, Krems, Morris, and Grossmann, 2018). However, the argument can be made that these approaches cause important information to be lost, especially as from a theoretical standpoint most cultural change researchers are interested in long term trends rather than short term fluctuations, and as the indicators we tend to use in this research may contain a degree of noise

\footnotetext{
${ }^{1}$ https://xwiki.nbirn.org:8443/xwiki/bin/view/Function-BIRN/AutomatedQA
} 
or error. Alternative approaches include using Granger Causality tests (e.g. Grossmann and Varnum, 2015), correcting significance thresholds by simulating bootstrapped null distributions with datasets containing the same number of data points and the same degrees of first-order autocorrelation observed in the actual time series a method devised by Tiokhin and Hruschka (2016) (Varnum, Krems, Morris, and Grossmann, 2018), or the using advanced forecasting methods like auto-ARIMA, an algorithm developed by Hyndman and Khandakar (2008) (e.g. Varnum, 2018; Varnum, Krems, Morris, and Grossmann, 2018).

Auto-ARIMA is an algorithm which generates the optimal forecasting model based on error residual reduction. It assesses the extent to which a variety of models including autoregressive components of the respective time series, moving averages, and various types of differencing fit the data and assesses the contribution made by theorized exogenous factors above and beyond the contributions made by autoregressive components of the time series. If the optimal model includes the exogenous variable, then researchers can have confidence that the relationship between two time-series is not likely spurious even in the presence of a high degree of temporal autocorrelation among both time series. Auto-ARIMA also generates forecast for future values, and this technique can be used to assess the validity of these models by comparing them with real future observations. If relationships between two highly auto-correlated timeseries hold when using a combination of these approaches to dealing with autocorrelation, we suggest that researchers should have confidence that these relationships are not likely to be spurious. Thus we highly recommend that researchers use at least one of these methods if a high degree of temporal auto-correlation is present in at least one of their time series in order to improve confidence in the conclusions that they draw.

\section{Controlling for Alternative Explanations and Forecasting the Future}

We also have some recommendations for ensuring rigor in a neuroscience of cultural change, and in cultural change research more broadly. First, we recommend that researchers demonstrate that their models are robust. In the simplest sense this involves demonstrating that a proposed association between an exogenous factor(s) (i.e. changes in GDP, pathogen prevalence, climate, inequality, etc.) and dependent variables holds when controlling for other factors that might plausibly explain the effect. Unfortunately, this is not yet common in cultural change research, though it is standard in other types of correlational research in psychology and related disciplines. In our view it also involves dealing empirically with the possibility of spurious associations due to temporal autocorrelation using one or more of the methods we outlined in the previous section. Finally, we recommend that researchers studying cultural change, weather using neuroscience methods or not, publish forecasts for future trends based on their hypothesized models in addition to demonstrating relationships in past data (Varnum and Grossmann, 2017a). Whether future observations fit the predictions of these models derived from past observations should in our view be the gold standard for assessing their validity. And in truth, the promise of a science of cultural change has more to do with predicting the future than explaining the past.

\section{Summary and Conclusion}

We began this chapter by noting that human cultures are not static and provided evidence of changes in a wide variety of mental and behavioral phenomena over the past several decades 
and centuries in a number of societies. We suspect that the structure and function of our brains may have also changed during this time and may continue to do so in the decades and centuries to come. We generated several predictions for how changes in our social, physical, and technological environments may be reshaping our brains, and provided a broad outline for how such hypotheses may be tested in the future. Although others have speculated about ways in which recent developments may be affecting our brains, the present chapter, to our knowledge, represents the first roadmap for a rigorous and systematic study of this question and also provides the first concrete predictions for what types of neural changes we might expect to see in the coming years.

These changes may have important implications for forecasting trends in mental health in the coming decades, and may broaden our understanding of how environmental features may affect the risk for developing various forms of mental illness. Further, to the extent that relevant ecological changes occur at different rates around the globe, it may be that the risk of a variety of mental health problems may increase more dramatically in developing societies which face greater challenges in providing treatment for these illnesses. Governments, policy makers, NGO's, and clinicians may want to consider these issues when devising plans to improve mental health in the developing world.

We believe that there is now an exciting, though daunting, opportunity to create a field devoted to the study of how changes in the environment and society lead to changes in our brains at the scale of whole cultural groups. This would be an ambitious endeavor, but one that could be very fruitful. For the first time we have the capability to track how changes in our societies are impacting the way our brains are structured and function. This new field also represents an opportunity to build bridges across a variety of disciplines, including social psychology, clinical psychology, evolutionary psychology, economics, political science, and cultural neuroscience, and to connect theories and methods in a way that may produce a more complete understanding of human social dynamics than has previously been possible. 


\section{References}

Bakker, R., Tiesinga, P., \& Kötter, R. (2015). The scalable brain atlas: Instant web-based access to public brain atlases and related content. Neuroinformatics, 13(3), 353-366.

Bergman, O., Åhs, F., Furmark, T., Appel, L., Linnman, C., Faria, V., ... Eriksson, E. (2014). Association between amygdala reactivity and a dopamine transporter gene polymorphism. Translational Psychiatry, 4. http://doi.org/10.1038/tp.2014.50

Bianchi, E. C. (2016). American individualism rises and falls with the economy: Cross-temporal evidence that individualism declines when the economy falters. Journal of Personality and Social Psychology, 111(4), 567-584. http://doi.org/10.1037/pspp0000114

Bond, R., \& Smith, P. B. (1996). Culture and conformity: A meta-analysis of studies using Asch's line judgment task. Psychological Bulletin, 119(I), 111-137. http://doi.org/10.1037//0033-2909.119.1.111

Cai, H., Zou, X., Feng, Y., Liu, Y., \& Jing, Y. (2018). Increasing need for uniqueness in contemporary China: Empirical evidence. Frontiers in Psychology, 9(MAY), 1-7. http://doi.org/10.3389/fpsyg.2018.00554

Campbell, S., \& Macqueen, G. (2004). The role of the hippocampus in the pathophysiology of major depression. Journal of psychiatry \& neuroscience : JPN, 29(6), 417-426.

Canli, T., Omura, K., Haas, B. W., Fallgatter, A., Constable, R. T., \& Lesch, K. P. (2005). Beyond affect: A role for genetic variation of the serotonin transporter in neural activation during a cognitive attention task. Proceedings of the National Academy of Sciences, 102(34), 12224-12229. http://doi.org/10.1073/pnas.0503880102

Charnov, E. L. (1993). Life history invariants: Some explorations of symmetry in evolutionary ecology (Vol. 6). New York, NY: Oxford University Press.

Chiao, J. Y., \& Blizinsky, K. D. (2016). Cultural Neuroscience: Bridging cultural and biological sciences. In E. Harmon-Jones \& M. Inzlicht (Eds.), Social neuroscience: biological approaches to social psychology. New York, NY: Taylor \& Francis.

Del Giudice, M., Gangestad, S. W., \& Kaplan, H. S. (2015). Life history theory and evolutionary psychology. The Handbook of Evolutionary Psychology.

Etkin, A., \& Wager, T. D. (2007). Functional neuroimaging of anxiety: A meta-analysis of emotional processing in PTSD, social anxiety disorder, and specific phobia. The American Journal of Psychiatry, 164(10), 1476-1488. http://doi.org/10.1176/appi.ajp.2007.07030504

Fan, L., Li, H., Zhuo, J., Zhang, Y., Wang, J., Chen, L., ... Jiang, T. (2016). The human brainnetome atlas: A new brain atlas based on connectional architecture. Cerebral Cortex. http://doi.org/10.1093/cercor/bhw157

Fawcett, T. (2015). Avoiding common mistakes with time series, (January 28), [Blog post]. Retrieved from https://svds.com/avoiding-common-mistakes-with-time-series/

Flynn, J. R. (1987). Massive IQ gains in 14 nations: Waht IQ tests really measure. Psychological Bulletin, 101(2), 171-191. http://doi.org/10.1037/0033-2909.101.2.171

Flynn, J. R. (2007). What is intelligence? Beyonod the Flynn Effect. New York: Cambridge University Press.

Friedman, L., \& Glover, G. H. (2006). Report on a multicenter fMRI quality assurance protocol. Journal of Magnetic Resonance Imaging, 23(6), 827-839. http://doi.org/10.1002/jmri.20583

Gaffrey, M. S., Luby, J. L., Belden, A. C., Hirshberg, J. S., Volsch, J., \& Barch, D. M. (2011). Association between depression severity and amygdala reactivity during sad face viewing in depressed preschoolers: An fMRI study. Journal of Affective Disorders, 129(1-3), 364-370. 
http://doi.org/10.1016/j.jad.2010.08.031

Gardner, H. (2011). Frames of mind: The theory of multiple intelligences. New York, NY: BasicBooks.

Gauthier, I., Tarr, M. J., Moylan, J., Skudlarski, P., Gore, J. C., \& Anderson, A. W. (2000). The fusiform "face area" is part of a network that processes faces at the individual level. Journal of Cognitive Neuroscience, 12(3), 495-504. http://doi.org/10.1162/089892900562165

Gentile, B., Campbell, W. K., \& Twenge, J. M. (2014). Generational cultures. Culture reexamined: Broadening our understanding of social and evolutionary influences, 31-48.

Ghaem, O., Mellet, E., Crivello, F., Tzourio, N., Mazoyer, B., Berthoz, A., \& Denis, M. (1997). Mental navigation along memorized routes activates the hippocampus, precuneus, and insula. NeuroReport, 8(3), 739-744. http://doi.org/10.1097/00001756-199702100-00032

Greenfield, P. M. (2013). The changing psychology of culture from 1800 through 2000. Psychological Science, 24(9), 1722-1731. http://doi.org/10.1177/0956797613479387

Greenfield, P. M. (2016). Social change, cultural evolution, and human development. Current Opinion in Psychology, 8(Figure 1), 84-92. http://doi.org/10.1016/j.copsyc.2015.10.012

Greenfield, P. M. (2017). Cultural change over time: Why replicability should not be the gold standard in psychological science. Perspectives on Psychological Science, 12(5), 762-771.

Grossmann, I., \& Varnum, M. E. W. (2015). Social structures, infectious diseases, disasters, secularism and cultural change in America. Psychological Science, (1980), 0956797614563765-. http://doi.org/10.1177/0956797614563765

Hamamura, T. (2012). Are cultures becoming individualistic? A cross-temporal comparison of individualism-collectivism in the United States and Japan. Personality and Social Psychology Review, 16(1), 3-24. http://doi.org/10.1177/1088868311411587

Hamamura, T., \& Septarini, B. G. (2017). Culture and self-esteem over time: A cross-temporal meta-analysis among Australians, 1978-2014. Social Psychological and Personality Science, 8(8), 904-909. http://doi.org/10.1177/1948550617698205

Hamamura, T., \& Xu, Y. (2015). Changes in Chinese culture as examined through changes in personal pronoun usage. Journal of Cross-Cultural Psychology, 46(7), 930-941. http://doi.org/10.1177/0022022115592968

Hampton, R. S., \& Varnum, M. E. W. (2018a). The cultural neuroscience of emotion regulation. Culture and Brain, 6, 130-150.

Hampton, R. S., \& Varnum, M. E. W. (2018). Do cultures vary in self-enhancement? ERP, behavioral, and self-report evidence. Social Neuroscience, 13, 566-578.

Han, S. (2013). How to identify mechanisms of cultural influences on human brain functions. Psychological Inquiry, 24(1), 37-41. http://doi.org/10.1080/1047840X.2013.765755

Han, S., \& Ma, Y. (2014). Cultural differences in human brain activity: A quantitative metaanalysis. NeuroImage, 99, 293-300. http://doi.org/10.1016/j.neuroimage.2014.05.062

Hyndman, R. J., \& Khandakar, Y. (2008). Automatic time series forecasting: The forecast package for R. Journal of Statistical Software, 27(3). http://doi.org/10.18637/jss.v027.i03

Iliev, R., Hoover, J., Dehghani, M., \& Axelrod, R. (2016). Linguistic positivity in historical texts reflects dynamic environmental and psychological factors. Proceedings of the National Academy of Sciences, 113(49), E7871-E7879. http://doi.org/10.1073/pnas.1620120114

Inglehart, R. (1997). Modernization and postmodernization: Cultural, economic, and political change in 43 societies. Princeton, NJ: Princeton University Press.

Inglehart, R., \& Welzel, C. (2005). Modernization, cultural change, and democracy: The human development sequence. New York: Cambridge University Press. 
Johnson, S. (2005). Everything Bad is Good for You: How Popular Culture is Making Us Smarter. Penguin: London.

Kanwisher, N., McDermott, J., \& Chun, M. M. (1997). The fusiform face area: A module in human extrastriate cortex specialized for face perception. The Journal of Neuroscience, 17(11), 4302-11. http://doi.org/10.1098/Rstb.2006.1934

Kanwisher, N., \& Yovel, G. (2006). The fusiform face area: A cortical region specialized for the perception of faces. Philosophical Transactions of the Royal Society B: Biological Sciences, 361(1476), 2109-2128. http://doi.org/10.1098/rstb.2006.1934

Kashima, Y. (2014). How can you capture cultural dynamics? Frontiers in Psychology, 5, 1-16. http://doi.org/10.3389/fpsyg.2014.00995

Kaufman, S. B. (2013). The complexity of greatness: Beyond talent or practice. New York, NY: Oxford University Press.

Kenrick, D. T., \& Griskevicius, V. (2015). Life history, fundamental motives, and sexual competition. Current Opinion in Psychology, 1, 40-44.

Kesebir, S., \& Kesebir, P. (2017). A growing disconnection from nature is evident in cultural products. Perspectives on Psychological Science, 12(2), 258-269.

Kim, H. S., \& Sasaki, J. Y. (2014). Cultural neuroscience: Biology of the mind in cultural contexts. Annual Review of Psychology, 65, 487-514. http://doi.org/10.1146/annurevpsych-010213-115040

Kitayama, S., \& Uskul, A. K. (2011). Culture, mind, and the brain: Current evidence and future directions. Annual Review of Psychology, 62, 419-49. http://doi.org/10.1146/annurevpsych-120709-145357

Kitayama, S., Varnum, M. E. W., \& Salvador, C. (in press). Cultural neuroscience. In D. Cohen \& S. Kitayama (Eds.), Handbook of Cultural Psychology (2nd ed.). New York, NY: The Guilford Press.

Kitayama, S., Yanagisawa, K., Ito, A., Ueda, R., Uchida, Y., \& Abe, N. (2017). Reduced orbitofrontal cortical volume is associated with interdependent self-construal. Proceedings of the National Academy of Sciences, 114(30), 7969-7974.

Lesthaeghe, R. J. (2015). The decline of Belgian fertility, 1800-1970. Princeton, NJ: Princeton University Press.

Liu, T. T. (2016). Noise contributions to the fMRI signal: An overview. NeuroImage, 143, 141151. http://doi.org/10.1016/j.neuroimage.2016.09.008

Maguire, E. A., Burgess, N., Donnett, J. G., Frackowiak, R. S. J., Frith, C. D., \& Okeefe, J. (1998). Knowing where and getting there. Science, 280(5365), 921-924.

Maguire, E. A., Gadian, D. G., Johnsrude, I. S., Good, C. D., Ashburner, J., Frackowiak, R. S. J., \& Frith, C. D. (2000). Navigation-related structural change in the hippocampi of taxi drivers. Proceedings of the National Academy of Sciences, 97(8), 4398-4403. http://doi.org/10.1073/pnas.070039597

Marcus, D. S., Harms, M. P., Snyder, A. Z., Jenkinson, M., Wilson, J. A., Glasser, M. F., ... Van Essen, D. C. (2013). Human Connectome Project informatics: Quality control, database services, and data visualization. NeuroImage, 80, 202-219. http://doi.org/10.1016/j.neuroimage.2013.05.077

Markus, H. R., \& Kitayama, S. (1991). Culture and the self: Implications for cognition, emotion, and motivation. Psychological Review, 98(2), 224-253. http://doi.org/10.1037/0033295X.98.2.224

Martin, S. F., Weerasinghe, S., \& Taylor, A. (2014). Humanitarian crises and migration: 
Causes, consequences and responses. New York, NY: Routledge.

Matthews, P. M. (2001). An introduction to functional magnetic resonance imaging of the brain. In P. M. Jezzard, P. M. Matthews, \& S. M. Smith (Eds.), Functional MRI-An Introduction to Methods (pp. 3-34). Oxford: Oxford University Press.

Nisbett, R. E., Peng, K., Choi, I., \& Norenzayan, A. (2001). Culture and systems of thought: Holistic versus analytic cognition. Psychological Review, 108(2), 291-310. http://doi.org/10.1037/0033-295X.108.2.291

Obradovich, N. (2017). Climate change may speed democratic turnover. Climatic Change, 140(2), 135-147.

Obradovich, N., Migliorini, R., Paulus, M. P., \& Rahwan, I. (2018). Empirical evidence of mental health risks posed by climate change. Proceedings of the National Academy of Sciences, 115(43), 10953-10958.

Obradovich, N., \& Fowler, J. H. (2017). Climate change may alter human physical activity patterns. Nature Human Behaviour, 1(5), 1-7. http://doi.org/10.1038/s41562-017-0097

Ogihara, Y. (in press). The rise in individualism in Japan: Temportal changes in family structure, 1947-2015. Journal of Cross-Cultural Psychology.

Oishi, S., Kesebir, S., \& Diener, E. (2011). Income inequality and happiness. Psychological Science, 22(9), 1095-1100. http://doi.org/10.1177/0956797611417262

Olivera, J. (2015). Changes in inequality and generalized trust in Europe. Social Indicators Research, 124(1), 21-41. http://doi.org/10.1007/s11205-014-0777-5

Patriquin, M. A., DeRamus, T., Libero, L. E., Laird, A., \& Kana, R. K. (2016). Neuroanatomical and neurofunctional markers of social cognition in autism spectrum disorder. Human Brain Mapping, 37(11), 3957-3978.

Pennebaker, J. W., \& Jordan, K. (2018). Cultural shifts in the presidents we choose. Presented at the $19^{\text {th }}$ annual meeting of the Society for Personality and Social Psychology, Atlanta, GA.

Pietschnig, J., \& Voracek, M. (2015). One century of global IQ Gains: A formal meta-analysis of the Flynn Effect (1909-2013). Perspectives on Psychological Science, 10(3), 282-306. http://doi.org/10.1177/1745691615577701

Putnam, R. D. (1995). Tuning in, tuning out: The strange disappearance of social capital in America. PS: Political Science \& Politics, 28(4), 664-683.

Putnam, R. D. (2000). Bowling alone: America's declining social capital. In L. Crothers \& C. Lockhart (Eds.), Culture and Politics: A Reader (pp. 223-234). New York, NY: Palgrave Macmillan. http://doi.org/10.1007/978-1-349-62397-6

Raven, J. (2000). The Raven's Progressive Matrices: Change and stability over culture and time. Cognitive Psychology, 41(1), 1-48. http://doi.org/10.1006/cogp.1999.0735

Redlich, R., Opel, N., Bürger, C., Dohm, K., Grotegerd, D., Förster, K., ... Dannlowski, U. (2018). The limbic system in youth depression: Brain structural and functional alterations in adolescent in-patients with severe depression. Neuropsychopharmacology, 43(3), 546-554. http://doi.org/10.1038/npp.2017.246

Roberts, B. W., \& Helson, R. (1997). Changes in culture, changes in personality: The influence of individualism in a longitudinal study of women. Journal of Personality and Social Psychology, 72(3), 641-651. http://doi.org/10.1037/0022-3514.72.3.641

Roser, M., \& Ortiz-Ospina, E. (2017). Global extreme poverty. Our World in Data, 1-38. Retrieved from https://ourworldindata.org/world-population-growth

Santos, H. C., Grossmann, I., \& Varnum, M. E. W. (2017). Class, cognition and cultural change 
in social class. In W. H. Brekhus \& G. Ingatow (Eds.), Oxford Handbook of Cognitive Sociology (p. 13). Oxford: Oxford University Press.

Schultz, R. T. (2005). Developmental deficits in social perception in autism: the role of the amygdala and fusiform face area. International Journal of Developmental Neuroscience, 23(2-3), 125-141.

Schultz, R. T., Grelotti, D. J., Klin, A., Kleinman, J., Van der Gaag, C., Marois, R., \& Skudlarski, P. (2003). The role of the fusiform face area in social cognition: implications for the pathobiology of autism. Philosophical transactions of the Royal Society of London. Series B, Biological sciences, 358(1430), 415-27.

Schuttenhelm, R. (2016). http://www.bitsofscience.org/graph-global-air-travel-increase-6848/

Sergent, J., Ohta, S., \& MacDonald, B. (1992). Functional neuroanatomy of face and object processing: A positron emission tomography study. Brain, 115, 15-36.

Siegle, G. J., Thompson, W., Carter, C. S., Steinhauer, S. R., \& Thase, M. E. (2007). Increased amygdala and decreased dorsolateral prefrontal BOLD responses in unipolar depression: Related and independent features. Biological Psychiatry, 61(2), 198-209. http://doi.org/10.1016/j.biopsych.2006.05.048

Simmons, A., Moore, E., \& Williams, S. C. (1999). Quality control for functional magnetic resonance imaging using automated data analysis and Shewhart charting. Magnetic Resonance in Medicine, 41(6), 1274-1278.

Sng, O., Neuberg, S. L., Varnum, M. E. W., \& Kenrick, D. T. (2018). The behavioral ecology of cultural variation. Psychological Review, 125, 714-745.

Stearns, S. C. (1992). The Evolution of Life Histories. Oxford: Oxford University Press.

Stein, M. B., Simmons, A. N., Feinstein, J. S., \& Paulus, M. P. (2007). Increased amygdala and insula activation during emotion processing in anxiety-prone subjects. American Journal of Psychiatry, 164(2), 318-327. http://doi.org/10.1176/ajp.2007.164.2.318

Sternberg, R. J. (1985). Implicit theories of intelligence, creativity, and wisdom. Journal of Personality and Social Psychology, 49(3), 607-627. http://doi.org/10.1037/00223514.49.3.607

Stone, D. M., Simon, T. R., Fowler, K. A., Kegler, S. R., Yuan, K., \& Holland, K. M. (2018). Vital signs: Trends in state suicide rates - United States , 1999 - 2016 and circumstances contributing to suicide — 27 States , 2015. Morbidity and Mortality Weekly Report, 67(22), 617-24. http://doi.org/10.15585/mmwr.mm6722a1

Thornton, A., \& Young-DeMarco, L. (2001). Four decades of trends in attitudes toward family issues in the United States: The 1960s through the 1990s. Journal of Marriage and Family, 63(4), 1009-1037. http://doi.org/10.1111/j.1741-3737.2001.01009.x

Tiokhin, L., \& Hruschka, D. (2017). No evidence that an Ebola outbreak influenced voting preferences in the 2014 elections after controlling for time-series autocorrelation: A commentary on Beall, Hofer, and Schaller (2016). Psychological Science, 28(9), 13581360.

Trahan, L., Stuebing, K. K., Hiscock, M. K., \& Fletcher, J. M. (2014). The Flynn Effect: A metaanalysis. Psychological Bulletin, 140(5), 1332-1360. http://doi.org/10.1037/a0037173.The

Triandis, H. (1995). Individualism \& Collectivism. Boulder: Westview Press.

Trzesniewski, K. H., Donnellan, M. B., \& Robins, R. W. (2008a). Do today's young people really think they are so extraordinary. Psychological Science, 19(2), 181-189.

http://doi.org/10.1111/j.1467-9280.2008.02065.x

Trzesniewski, K. H., Donnellan, M. B., \& Robins, R. W. (2008b). Is “Generation Me” really 
more narcissistic than previous generations? Journal of Personality, 76(4), 903-918. http://doi.org/10.1111/j.1467-6494.2008.00508.x

Twenge, J. M. (1997). Attitudes toward women, 1970-1995. Psychology of Women Quarterly, $21(1), 35-51$.

Twenge, J. M. (2015). Time period and birth cohort diffrences in depressive symptoms in the U.S., 1982-2013. Social Indicators Research, 121(2), 437-454. http://doi.org/10.1007/s11205-014-0647-1

Twenge, J. M., Abebe, E. M., \& Campbell, W. K. (2010). Fitting in or standing out: Trends in American parents' choices for children's names, 1880-2007. Social Psychological and Personality Science, 1(1), 19-25. http://doi.org/10.1177/1948550609349515

Twenge, J. M., \& Campbell, W. K. (2001). Age and birth cohort differences in self-esteem: A cross-temporal meta-analysis. Personality and Social Psychology Review, 5, 296-320. http://doi.org/10.1207/S15327957PSPR0504

Twenge, J. M., \& Campbell, W. K. (2018). Cultural individualism is linked to later onset of adult-role responsibilities across time and regions. Journal of Cross-Cultural Psychology, 49(4), 673-682.

Twenge, J. M., Campbell, W. K., \& Carter, N. T. (2014). Declines in trust in others and confidence in institutions among American adults and late adolescents, 1972-2012. Psychological Science, 25(10), 1914-1923. http://doi.org/10.1177/0956797614545133

Twenge, J. M., Campbell, W. K., \& Gentile, B. (2012a). Increases in individualistic words and phrases in American books, 1960-2008. PLoS ONE, 7(7). http://doi.org/10.1371/journal.pone.0040181

Twenge, J. M., Campbell, W. K., \& Gentile, B. (2012b). Male and female pronoun use in U.S. books reflects women's status, 1900-2008. Sex Roles, 67(9-10), 488-493. http://doi.org/10.1007/s11199-012-0194-7

Twenge, J. M., Campbell, W. K., \& Gentile, B. (2013). Changes in pronoun use in American books and the rise of individualism, 1960-2008. Journal of Cross-Cultural Psychology, 44(3), 406-415. http://doi.org/10.1177/0022022112455100

Twenge, J. M., \& Foster, J. D. (2008). Mapping the scale of the narcissism epidemic: Increases in narcissism 2002-2007 within ethnic groups. Journal of Research in Personality, 42(6), 1619-1622. http://doi.org/10.1016/j.jrp.2008.06.014

Twenge, J. M., Gentile, B., DeWall, C. N., Ma, D., Lacefield, K., \& Schurtz, D. R. (2010). Birth cohort increases in psychopathology among young Americans, 1938-2007: A crosstemporal meta-analysis of the MMPI. Clinical Psychology Review, 30(2), 145-154. http://doi.org/10.1016/j.cpr.2009.10.005

Twenge, J. M., Joiner, T. E., Rogers, M. L., \& Martin, G. N. (2018). Increases in depressive symptoms, suicide-related outcomes, and suicide rates among US adolescents after 2010 and links to increased new media screen time. Clinical Psychological Science, 6(1), 3-17.

Twenge, J. M., Konrath, S., Foster, J. D., Campbell, W. K., \& Bushman, B. J. (2008). Further evidence of an increase in narcissism among college students. Journal of Personality, 76(4), 919-928. http://doi.org/10.1111/j.1467-6494.2008.00509.x

Twenge, J. M., \& Park, H. (2017). The decline in adult activities among U.S. adolescents, 19762016. Child Development, 1-17. http://doi.org/10.1111/cdev.12930

United Nations, D. of E. and S. A. P. D. (2013). Trends in international migration.

United Nations, D. of E. and S. A. P. D. (2014). World Urbanization Prospects: The 2014 Revision, Highlights. Demographic Research. http://doi.org/10.4054/DemRes.2005.12.9 
Van de Vliert, E. (2013). Climato-economic habitats support patterns of human needs, stresses, and freedoms. Behavioral and Brain Sciences, 36(05), 465-480. http://doi.org/10.1017/S0140525X12002828

Varnum, M. E. W. (March, 2018). Making psycho-history a reality: The emerging science of cultural change. Presented at the Advances in Cultural Psychology Preconference at the $19^{\text {th }}$ annual meeting of the Society for Personality and Social Psychology, Atlanta, GA.

Varnum, M. E. W., \& Grossmann, I. (2016). Pathogen prevalence is associated with cultural changes in gender equality. Nature Human Behaviour, 1. http://doi.org/10.1038/s41562016-0003

Varnum, M. E. W., \& Grossmann, I. (2017a). Cultural change: The how and the why. Perspectives on Psychological Science, 12(6), 956-972. http://doi.org/10.1177/1745691617699971

Varnum, M. E. W., \& Grossmann, I. (2017b). Socio-ecological factors are linked to changes in prevalence of contempt over time. Behavioral and Brain Sciences, 40.

Varnum, M. E. W., \& Grossmann, I. (2018). The wealth->life history->innovation account of the industrial revolution is largely inconsistent with empirical time series data. Unpublished manuscript.

Varnum, M. E. W., Grossmann, I., Kitayama, S., \& Nisbett, R. E. (2010). The origin of cultural differences in cognition: The Social Orientation Hypothesis. Current Directions in Psychological Science, 19(1), 9-13. http://doi.org/10.1177/0963721409359301

Varnum, M. E. W., \& Hampton, R. S. (2017). Cultures differ in the ability to enhance affective neural responses. Social Neuroscience, 12, 594-603.

Varnum, M. E. W., Krems, J. A., Morris, C., \& Grossmann, I. (2018). Greater information saturation is linked to increasing preference for simpler cultural products. Manuscript submitted for publication.

Vigen, T. (2015). Spurious correlations. New York: Hachette Books.

Weisskoff, R. M. (1996). Simple measurement of scanner stability for functional NMR imaging of activation in the brain. Magnetic Resonance in Medicine, 36(4), 643-645. http://doi.org/10.1002/mrm.1910360422

Wetzel, E., Brown, A., Hill, P. L., Chung, J. M., Robins, R. W., \& Roberts, B. W. (2017). The narcissism epidemic is dead; Long live the narcissism epidemic. Psychological Science, 28(12), 1833-1847. http://doi.org/10.1177/0956797617724208

Zeng, R., \& Greenfield, P. M. (2015). Cultural evolution over the last 40 years in China: Using the Google Ngram viewer to study implications of social and political change for cultural values. International Journal of Psychology, 50(1), 47-55. http://doi.org/10.1002/ijop.12125

Zhu, Y., Zhang, L., Fan, J., \& Han, S. (2007). Neural basis of cultural influence on selfrepresentation. Neuroimage, 34(3), 1310-1316. 